\title{
Energia e sociedade
}

\section{JOAQUIM FRANCISCO DE CARVALHO ${ }^{I}$}

\section{Introdução}

$\mathrm{H}$

Á VESTÍGIOS de utilização do fogo por hominídeos, remontando a mais de 1,9 milhão de anos (Bowman et al., 2009). E entre duzentos mil e cinquenta mil anos atrás, o Homo neanderthalensis usava o fogo para a cocção de alimentos (Jacomy, 1990).

$\mathrm{Na}$ medida em que iam sendo descobertas e usadas, as fontes de energia imprimiam novos rumos para a evolução da sociedade humana.

As primeiras civilizações só apareceram de fato com a cultura irrigada de cereais, há cerca de seis mil anos, na Mesopotâmia, tendo como fonte de energia a força muscular, complementada pela energia cinética dos cursos de água, além da tração animal e da lenha. O fogo já era então usado de forma controlada (Hémery et al., 1991).

$\mathrm{Na}$ Ucrânia, há mais de quatro mil anos, o emprego de cavalos para tração e montaria viabilizou o transporte de alimentos e madeira de regiões distantes, permitindo que a lenha pudesse ser usada como fonte regular de energia para olarias e fundições primordiais, acarretando profundas transformações econômicas e sociais, que se estenderam na direção da Europa ocidental, na Idade do Cobre (Anthony et al., 1991).

Embora a madeira seja um combustível potencialmente renovável, a tecnologia para aproveitá-la em larga escala - a silvicultura - ficou estagnada durante muitos séculos. Como as populações primitivas eram rarefeitas (Tabela 1), o próprio ciclo natural assegurava a regeneração e reposição das florestas.

Depois, ao longo dos séculos, foram-se agregando outras fontes de energia, tais como os ventos (barcos a vela, moinhos de vento etc.), o óleo de baleia, a turfa etc.

Tabela 1 - Evolução da população mundial, de 6.000 a.C, até a Revolução Industrial

\begin{tabular}{l|c|c|c|c|c|c}
\hline Ano & 6.000 a.C. & 1 a.D. & 1.000 a.D. & 1.500 a.D. & 1.600 a.D. & 1.750 a.D. \\
\hline $\begin{array}{l}\text { População } \\
\text { (milhões) }^{*}\end{array}$ & $\sim 7$ & $\sim 300$ & $\sim 310$ & $\sim 500$ & $\sim 560$ & $\sim 800$ \\
\hline
\end{tabular}

Fontes: Durand, 1974; Haub, 1995; United Nations, 1999.

* Médias aritméticas dos valores apresentados nas fontes consultadas

Os primeiros sinais de manejo florestal voltado para a obtenção de madeira de construção e lenha só surgiram na China, durante a Dinastia Han (206 a.C. 
a 220 a.D.) e, mais tarde, na Dinastia Ming, de 1368 a 1644 (Hémery et al., 1991).

No Ocidente, a silvicultura - ainda de forma rudimentar - teve seus primórdios na Idade Média, quando as terras eram controladas pelos senhores feudais.

A silvicultura como atividade econômica planejada teve suas bases científicas formuladas e desenvolvidas na Alemanha, nos séculos XVIII e XIX.

Toda a tecnologia industrial alemã do século XVIII baseava-se na madeira, a começar pelos processos de mineração e refino de metais, que dependiam de troncos, para suporte das galerias, e de carvão vegetal, para a redução dos minérios e geração de calor.

A madeira era o combustível universal, além de ser o único material de construção que se oferecia como alternativa à pedra e à alvenaria, para as casas e obras públicas. Era, também, o material por excelência da construção naval.

$\mathrm{Na}$ Alemanha, até fins do século XIX, a madeira era mais importante do que hoje são o aço, o carvão mineral, o petróleo etc. Não se podia, pois, permitir que as reservas florestais se esgotassem. Começou assim o desenvolvimento de uma economia florestal sistemática e, já no início do século XIX, existiam naquele país cursos regulares de silvicultura.

Na Inglaterra, no século XVIII, as florestas estavam sendo devastadas pela extração de lenha e madeiras, especialmente para a construção de navios para a armada.

O carvão, no entanto, era abundante e barato, chegando mesmo a aflorar à superfície do terreno, em determinadas regiões, de modo que, em pouco tempo, essa fonte de energia passou à frente da madeira. Com isso, as jazidas carboníferas mais acessíveis foram se esgotando e a exploração desceu ao subsolo, em poços e minas frequentemente inundadas, que tornavam indispensável o bombeamento.

Essa necessidade está na origem da tentativa de empreendedores ingleses e escoceses, de empregar a máquina a vapor para o acionamento de bombas em minas de carvão. A primazia no emprego das propriedades expansivas do ar aquecido para o acionamento de mecanismos coube, entretanto, aos mecânicos da escola criada por Alexandre, o Grande, que elevou a tecnologia grega a um alto nível de desenvolvimento. Destacam-se aí os nomes dos grandes mecânicos Archiyas, Ctébsibios e Philon de Bisâncio, que viveram entre os séculos I e IV a.C. (Jacomy, 1990).

À mesma escola pertenceu Herão de Alexandria, que pela primeira vez usou as propriedades expansivas do vapor para acionar um dispositivo mecânico, a Eolípila.

Tratava-se de uma esfera alimentada a vapor, que girava sob o empuxo de dois jatos escapando de tubos ajustados de lados opostos. Como ainda não se tinham desenvolvido materiais e técnicas de caldeiraria adequadas, não se construiu nenhuma Eolípila de dimensões aproveitáveis para fins práticos. 
A primeira máquina a vapor operativa foi a bomba desenhada e construída em 1698 por Thomas Savery, para bombear água de minas (Barghini, 1971).

Essa máquina não tinha nenhum êmbolo ou pistão, usando, para aspirar a água, apenas o vácuo criado pela condensação do vapor, para lançá-la à superfície por meio de um arranjo de válvulas, mas diversos problemas técnicos impediram-na de produzir os resultados esperados.

Em 1712, o comerciante de máquinas de mineração Thomas Newcomen, com o apoio do físico Robert Hook, desenvolveu uma máquina a vapor efetivamente operativa que, posteriormente, foi aperfeiçoada por James Watt e passou a ser empregada em fábricas, locomotivas, navios etc. Sem essa máquina, a Revolução Industrial não teria tomado o rumo que tomou.

No século XIX, entre os anos 1830 e 1840, o emprego da eletricidade nas comunicações (telégrafo) e na metalurgia (galvanoplastia) despertou o interesse dos empresários industriais, mas o grande impulso só veio em 1878, quando Thomas Edison colocou em condições de uso a lâmpada incandescente de filamento e Werner Siemens apresentou a primeira locomotiva elétrica.

Um pouco mais tarde, Nikola Tesla desenvolveu o motor de corrente alternada, graças ao qual a eletricidade passou a ser usada nas fábricas, para o acionamento mecânico.

Ao mesmo tempo aperfeiçoava-se a turbina hidráulica, como alternativa para a turbina a vapor até então usada na geração elétrica. Apareceram assim as primeiras hidroelétricas de certo porte, com linhas de transmissão que permitiam o uso da energia dos rios, nas cidades e nas fábricas.

Há registros históricos datando do quarto milênio antes de Cristo, relativos a usos de petróleo (do grego $\pi \varepsilon \tau \rho \varepsilon ́ \lambda \alpha \iota$, pelo latim petra $=$ pedra + oleum $=$ óleo) no Oriente Médio, onde são frequentes as exsudações e afloramentos de hidrocarbonetos.

No início da Era Cristã, os árabes já o usavam em lâmpadas a óleo e, no século XIII, existia uma primitiva indústria do petróleo, quando as ruas de Bagdá eram pavimentadas com alcatrão. Ainda no século XIII, Marco Polo descreveu campos de petróleo, no Azerbaijão (Petroleum, 2007).

Mas foi na virada dos séculos XIX para XX que o petróleo passou a ser usado em larga escala - era a "idade do petróleo" que começava.

Embora o carvão ainda seja um dos combustíveis mais consumidos, foi o petróleo que consolidou o modelo industrial moderno, caracterizado pela produção em massa, com setores dinâmicos - como o automobilístico, o naval, o ferroviário, o de máquinas e equipamentos etc. - forçando o desenvolvimento tecnológico de indústrias satélites, ligadas às respectivas linhas de produção.

$\mathrm{Na}$ medida em que ficavam mais problemáticas, as velhas fontes iam sendo complementadas - ou substituídas - por novas fontes, mais eficientes. Assim, a força muscular foi complementada pela lenha e pela tração animal, que por sua vez foi complementada pela energia das águas e dos ventos etc. Depois veio o 
carvão, que foi complementado pelo petróleo - ou por esse substituído, na indústria, nos transportes e nos modernos sistemas agroindustriais.

Concomitantemente, as matrizes energéticas iam se ajustando a essas fontes.

Até o presente não foram encontrados substitutos comparáveis ao petróleo e ao gás natural no que diz respeito à densidade energética, à transportabilidade e a outras características que lhes conferem qualidades ideais para o uso em larga escala nos transportes, na indústria e na agricultura.

O petróleo e o gás natural não são renováveis, de modo que o desenvolvimento subsequente à Revolução Industrial tem-se apoiado em bases fisicamente insustentáveis.

O petróleo abundante e barato ofereceu as condições básicas para o vertiginoso desenvolvimento da indústria automobilística, com seus fornecedores e subfornecedores - e uma poderosa estrutura de comercialização que se estende por todo o mundo em paralelo à rede de distribuição de combustíveis.

Desde as primeiras décadas do século passado, a indústria automobilística vem exercendo um papel de paradigma para a moderna civilização humana. Transformado em suprema aspiração de posse das famílias, o automóvel condicionou a evolução social e consagrou o transporte individual, influenciando fortemente a arquitetura das cidades modernas e o próprio urbanismo, acarretando importantes mudanças no modo de vida das pessoas.

Por dependerem diretamente de produtos da indústria automobilística, os atuais modelos de ocupação do território, urbanização e uso dos solos constituem mesmo a imagem da "idade do petróleo". A indústria automobilística e o motor de combustão interna estão presentes no mundo inteiro e os automóveis, ônibus, caminhões e tratores fazem parte do cotidiano de boa parte da humanidade, de sorte que qualquer turbulência que afete a produção do complexo industrial-comercial-financeiro direta ou indiretamente ligado a essa indústria reflete-se diretamente sobre toda a economia mundial, em particular sobre o nível de emprego.

Esse é um dos motivos que contribuem para colocar as reservas estratégicas de petróleo no foco dos principais conflitos que têm dominado a cena mundial nas últimas décadas, sobretudo no Oriente Médio, mas também no mar Cáspio, na África e no mar da China, com potencial para chegar à América Latina.

A chamada "revolução verde" deveu-se, em última análise, aos fertilizantes e pesticidas de origem petroquímica e à mecanização das atividades rurais, alimentada a combustíveis derivados do petróleo, tudo isso em descompasso com o ciclo de regeneração natural dos solos (Kunstler, 2005).

A globalização da economia também foi fruto da abundância e modicidade do petróleo que - transportado por grandes petroleiros - se tornava disponível no mundo inteiro, permitindo a instalação de fábricas em países da Ásia, da África e da América Latina, onde populações que vivem no limiar da subsistência 
oferecem mão de obra por uma fração do custo da oferecida nos países ditos desenvolvidos (Kunstler, 2005).

Há alternativas para alguns dos atuais usos do petróleo ou do gás.

Os biocombustíveis podem ser usados para os transportes, enquanto as fontes hidráulica, eólica, fotovoltaica e os próprio biocombustíveis são usadas em produção de energia elétrica.

Em países que não possuem essas fontes, o urânio tem sido usado para a geração de eletricidade.

Mas em aplicações vitais, como a produção, transporte e distribuição de alimentos, essas alternativas, isoladamente ou em conjunto, não poderão substituir, nas atuais escalas, o petróleo e o gás natural.

As usinas eletronucleares surgiram na década de 1950, cercadas de contradições provocadas, de um lado, por sua imagem destrutiva, ligada à devastação causada pelas bombas de urânio e plutônio, lançadas sobre Hiroshima e Nagasaki, e, de outro lado, pela imagem favorável, associada aos radiofármacos e às aplicações biomédicas dos radioisótopos.

A primeira central nuclear comercial do mundo entrou em operação em 1955, em Calder Hall, Inglaterra. Era um reator moderado a grafita e refrigerado a gás (tipo Magnox) e sua potência era de apenas 9 MW elétricos.

Depois, ainda em Calder Hall, foram instalados outros reatores Magnox, com potências começando em $50 \mathrm{MW}$ e chegando até $600 \mathrm{MW}$. Embora tenham operado bem, a eficiência térmica e o burnup daqueles reatores eram baixos, em parte por limitações impostas pelos danos causados pelos fluxos de nêutrons na liga metálica de revestimento dos combustíveis nucleares (liga de magnésio, com pequenas proporções de alumínio e berílio).

A indústria nuclear civil cresceu muito a partir do uso dos reatores a água leve pressurizada, graças, principalmente, ao fato de que grande parte dos investimento em $\mathrm{P} \& \mathrm{D}$ voltado para o desenvolvimento da tecnologia básica desses reatores veio dos orçamentos militares do governo americano, com os investimentos na tecnologia dos reatores de dimensões adequadas para equipar submarinos a propulsão nuclear.

Empresas como a Westinghouse, a General Electric e outras aproveitaram aqueles investimentos para viabilizar economicamente o desenvolvimento de reatores de potência em escala comercial e, posteriormente, negociaram os direitos sobre a engenharia básica das usinas equipadas com reatores a água leve, com a estatal francesa Framatome e com a alemã KWU, subsidiária da Siemens.

A partir dos acidentes de Three Mile Island, nos Estados Unidos (1979), Chernobyl, na Ucrânia, junto à Bielorússia (1986) e, principalmente, Fukushima, no Japão, a indústria nuclear tem enfrentado uma forte oposição da opinião pública, embora em alguns países o parque nuclear seja uma importante fonte geradora do sistema elétrico - se não a principal, como no caso da França. 


\section{A explosão demográfica}

A ilusão de que a tecnologia sempre daria ao homem capacidade para sustentar grandes populações em territórios pequenos colocou em posição secundária a milenar preocupação humana com o problema das dimensões da população relativamente aos territórios ocupados.

Embora na Antiguidade clássica ainda não existisse uma ciência da demografia, o problema do crescimento da população foi objeto de reflexões, entre outros, de Platão (427 a.C.- 347 a.C.), que chegou a pensar em um número ideal de habitantes para a cidade (Platão, 2006, p.99-101); e de Aristóteles (384 a.C.- 322 a.C.), que se preocupou com o crescimento desproporcional do número de magistrados em relação ao de artesãos, em face da limitação das terras disponíveis para cada estrato social (Aristóteles, 2000).

Já na Idade Moderna, encontramos, por exemplo, o enciclopedista Condorcet (1743-1794) que, em seu Esquisse d'un tableau historique des progrès de l'esprit humain, vaticinou que se o aumento da população ultrapassasse a capacidade (da natureza) de produzir meios de subsistência, haveria uma "diminuição da felicidade" (Condorcet, 1798).

O mais conhecido estudo sobre a questão foi, provavelmente, o "Ensaio sobre o princípio da população", de Thomas Malthus (1766-1834), para quem a expansão demográfica - que segue em progressão geométrica - seria contida pela escassez de alimentos, cuja produção cresce apenas em progressão aritmética.

John Stuart Mill (1806-1873), em seu livro The principles of political economy (capítulo 6 - "Of the Stationary State"), coloca-se ao lado de Malthus e do Marquês de Condorcet, posição a que se opunha, verbi gratia, a poderosa corrente dos seguidores do pensamento do Conde de Saint-Simon (1760-1825): "a cada um segundo sua capacidade, a cada capacidade segundo seu trabalho".

O progresso industrial alimentado a petróleo abundante e barato enfraqueceu a corrente - chamada "malthusiana" - daqueles que se preocupavam com o crescimento da população, com o caráter finito dos recursos naturais, com a correlação entre o desenvolvimento e o uso de energia, e com o fato de que a vida, como a conhecemos, depende da conversão de fatores de baixa entropia (os recursos naturais) em fatores de alta entropia.

Não havia interesse prático por temas ligados às inter-relações entre demografia, desenvolvimento social e uso de recursos naturais.

Um dos primeiros estudiosos a abordar a questão - ainda que se restringindo a aspectos isolados - foi o sociólogo e filósofo positivista inglês Herbert Spencer (1820-1903), para quem o uso de energia seria responsável pelas diferenças materiais entre as sociedades, e a humanidade poderia chegar à perfeição com base em concepções científicas avançadas para a época, tais como o primeiro princípio da termodinâmica e a teoria da evolução.

Outro foi o biólogo, urbanista e sociólogo escocês Sir Patrick Geddes 
(1854-1932), que, em seus trabalhos sobre planejamento urbano, introduziu os conceitos de região e de conurbação, e procurou definir uma unidade de medida comum, para explicar as correlações entre o uso de recursos materiais e o desenvolvimento econômico e social.

Até então os poucos que se interessavam pelo assunto consideravam que a evolução da sociedade para estágios superiores implicava o aumento do consumo de energia e o problema era tratado no contexto do primeiro princípio da termodinâmica.

Em 1909, no livro Energetische, o químico teuto-letão Friedrich Wilhelm Ostwald (1853-1932), ganhador do Prêmio Nobel de 1909 por seus trabalhos sobre catálise e equilíbrio químico, sustentava que toda evolução social baseia-se na transformação de energia primária (rohe Energie) em energia útil (Nutzenergie).

Pouco depois de Ostwald, outro ganhador do Prêmio Nobel de Química, o inglês Frederick Soddy (1877-1956), assinalou que, não podendo ser reciclada, a energia colocaria limites para as atividades da sociedade. Introduzia-se, assim, a segunda lei da termodinâmica, nas questões econômicas (Rosa et al., 1988).

A partir da Exposição Universal de Chicago, de 1933, cujo lema foi "A ciência descobre, a indústria aplica, o Homem se adapta", a ideia de que o engenho humano acabaria encontrando uma solução para o problema da limitação dos recursos naturais ganhou força na corrente dominante do pensamento econômico. Assim, essa corrente consagrou o dogma de que o crescimento da produção resolve todos os problemas que surgirem.

Mais tarde, graças às pesquisas do estatístico e economista romeno Nicholas Georgescu-Roegen (1906-1994), a corrente malthusiana conquistou importantes seguidores, incomodando a tal ponto a poderosa corrente antimalthusiana (também chamada neoclássica) - principalmente nos Estados Unidos, onde Georgescu-Roegen lecionou de 1950 a 1976 - que citar seus trabalhos equivalia a apelar para uma ciência menor.

O prejuízo causado às ciências sociais, econômicas e políticas pelo ostracismo em que foram lançados Georgescu-Roegen e seus seguidores (chamados "economistas ecológicos") reflete-se, entre outras coisas, no atraso sofrido pelas pesquisas sobre as inter-relações entre demografia, meio ambiente e desenvolvimento econômico.

Disso resultou a prática inexistência de políticas públicas à altura da importância do problema da expansão demográfica - em particular de políticas especificamente voltadas para o planejamento familiar.

A revolução verde e os sistemas de transporte de cargas e conservação e comercialização de produtos agrícolas favoreceram a explosão demográfica que, dos anos 1950 a 2008, isto é, em cerca de 65 anos, elevou a população mundial de 2,5 bilhões para 6,6 bilhões de habitantes, como mostra a Tabela 2. 
Tabela 2 - População mundial, de 1750 até o presente

\begin{tabular}{l|c|c|c|c|c|c}
\hline ANO & 1750 & 1850 & 1950 & 1970 & 1990 & 2008 \\
\hline População (bilhões) & 0,8 & 1,2 & 2,5 & 3,7 & 5,3 & 6,6 \\
\hline
\end{tabular}

Fontes: Cipolla (1964, p.99) e United Nations (1999).

E os governos nada faziam, até porque, para os principais economistas antimalthusianos, que dominavam o pensamento econômico, não se devia fazer nada para conter a expansão demográfica, pois essa promovia um vigoroso crescimento do consumo, portanto da produção e da economia como um todo. Pela óptica deles - que é de curto alcance -, a capacidade de suporte dos territórios é irrelevante, como também o é a capacidade da biosfera, para absorver os resíduos, a poluição gerada, enfim o "lixo" gerado. Para eles o crescimento da economia resolve todos os problemas.

Se as tendências das últimas seis décadas permanecerem inalteradas - e se antes não sobrevier uma catástrofe, causada pela escassez de alimentos e de água -, a população mundial deverá chegar a 7,5 bilhões em 2020. A Divisão Populacional da ONU chegou a prever que ultrapassaria dez bilhões em 2050; entretanto, constatou-se que os índices de natalidade têm caído nos últimos anos e aquelas estimativas foram revistas para baixo, prevendo-se que o patamar de estabilização será atingido em 2050, com a população chegando a nove bilhões, depois de passar pelos números indicado na Tabela 3.

Tabela 3 - Projeção da população mundial até 2050

\begin{tabular}{l|c|c|c|c}
\hline ANO & 2010 & 2020 & 2030 & 2050 \\
\hline População (bilhões) & 6,8 & 7,5 & 8,1 & 9,0 \\
\hline
\end{tabular}

Fonte: United Nations (1999).

Nos últimos quinze a vinte anos, por força das crises do petróleo e da tomada de consciência, pela sociedade, dos danos ambientais provocados pelas emissões de gases de estufa, as ideias de Georgescu-Roegen e outros economistas ecológicos estão, aos poucos, voltando à tona, principalmente na Europa - pelo menos como tema para pesquisas importantes, integrando economia, engenharia, ecologia e políticas públicas.

Assim, o problema da explosão demográfica tem sido objeto de muitos estudos acadêmicos, principalmente em conexão com problemas ligados à fome e à proliferação de epidemias nos países mais pobres da África e da Ásia.

No Brasil, dos 9,93 milhões de habitantes recenseados no Primeiro Recenseamento Geral do Império, realizado em 1872, a população chegou a 51,9 milhões, em 1950. Em seguida - acompanhando a explosão demográfica mundial - subiu para 187,5 milhões em 2008, como indica a Tabela 4. 
Tabela 4 - População brasileira, de 1872 até o presente (em milhões de habitantes)

\begin{tabular}{l|c|c|l|l|l|l|l|l}
\hline Ano & 1872 & 1900 & 1920 & 1950 & 1960 & 1980 & 2000 & 2008 \\
\hline População & 9,9 & 17,3 & 30,6 & 51,9 & 70,1 & 117,9 & 169,8 & 187,5 \\
\hline
\end{tabular}

Fonte: IBGE.

Tal crescimento concentrou-se nas regiões metropolitanas. Em 1950, a taxa de urbanização brasileira era de apenas 36\%. Em 1965 era de 50\%, chegou a 76\% em 1995 e atingiu 84\% em 2010.

Esse vertiginoso processo é uma das causas dos atuais problemas de habitação, transportes, poluição atmosférica, saúde pública, saneamento básico e criminalidade - sem que se tenha adotado uma política consentânea de planejamento familiar.

Em algumas universidades e instituições de pesquisa brasileiras, particularmente no Laboratório Interdisciplinar de Meio Ambiente do PPE/Coppe/ UFRJ e no Departamento de Economia da FEA/USP (nesse caso por iniciativa ainda não institucionalizada de alguns pesquisadores), as ideias de Georgescu-Roegem começam a ser objeto de estudos, que entretanto ainda são colocados no limbo pela corrente dominante do pensamento econômico.

\section{Desenvolvimento tecnológico, urbanização e consumo de energia no Brasil}

A história da energia no Brasil começou a mudar de rumo a partir da Segunda Guerra Mundial. Até 1940, a principal fonte primária de energia do país era a lenha, que respondia por mais de $75 \%$ do consumo energético.

Depois da guerra, os processos de urbanização e industrialização e o consequente desenvolvimento dos transportes rodoviários induziram um rápido crescimento do consumo de energia, levando o país a implantar dois sistemas fundamentais, o elétrico - para alimentar as cidades, o setor de serviços e uma parte das indústrias, e o do petróleo e gás - para suprir os transportes e outra parte das indústrias.

Nas linhas a seguir apresenta-se uma síntese histórica das principais etapas da formação do sistema energético brasileiro.

Entre os primeiros registros de estudos de autores brasileiros sobre a importância da madeira como lenha e material de construção em geral podem ser citados os trabalhos de José Bonifácio de Andrada e Silva ("Memória sobre a necessidade e utilidade do plantio de novos bosques em Portugal" - Lisboa, Typ. da Academia de Ciências, 1813); de Baltazar da Silva Lisboa ("Riquezas do Brasil em madeiras de construção e carpintaria" - Rio de Janeiro, Biblioteca Nacional, 1823) e de Francisco Freire Alemão ("Breve notícia sobre a colleção de madeiras do Brasil” - Rio de Janeiro, Typ. Nacional, 1867). No início de século XX surgiu, em São Paulo, o nome de Navarro de Andrade, com o mérito de ter iniciado os reflorestamentos de grande escala, especificamente planejados para 
fornecer matéria-prima florestal para as indústrias de celulose, além de lenha, dormentes e postes, para a Companhia Paulista de Estradas de Ferro. Décadas depois veio, no plano federal, Luís Simões Lopes, que, em 1937, concretizou os antigos planos e recomendações de botânicos, geólogos e geógrafos, como Alberto Loefgren, José Hubmeyer e o Barão Homem de Mello, criando o primeiro Parque Nacional do Brasil, na Serra de Itatiaia (Carvalho, 1983).

O emprego do álcool para fins combustíveis e industriais já era estudado no início do século passado. Em 1922 foram realizadas, na Escola Politécnica, diversas experiências de uso de álcool em motores de ciclo Otto (Menezes, 1980).

Na década seguinte foi criada a Comissão de Estudos do Álcool Motor (Ceam), para estudar a viabilidade do emprego do álcool como combustível e como aditivo para a gasolina que tinha entre os seus objetivos o de incentivar a produção de álcool em destilarias anexas às usinas instaladas pelo Estado, com a finalidade de equilibrar a oferta (e os preços) do açúcar, mediante o esmagamento de parte da cana para a produção de álcool.

Em 1933 foi criado o Instituo do Açúcar e do Álcool (IAA), com a missão de regular e equalizar o mercado de açúcar, obrigando a que parte da cana fosse destinada à fabricação de álcool anidro.

Até o início dos anos 1970, o álcool foi considerado um subproduto da indústria açucareira. Em 1973, com a crise do petróleo, ganharam impulso os estudos sobre o emprego do álcool como combustível complementar da gasolina. Em junho de 1975 foi instituído o Plano Nacional do Álcool e, em novembro do mesmo ano, foi criado o Programa Nacional do Álcool (Proálcool), tendo por objetivo a substituição, em larga escala, dos combustíveis derivados de petróleo por álcool, e, paralelamente, o apoio ao desenvolvimento de tecnologia adequada para a adaptação, ao álcool, dos motores Otto a gasolina, até então usados pelas montadoras de automóveis instaladas no Brasil (Menezes, 1980).

O Proálcool desenvolveu-se aceleradamente até meados da década de 1990, com uma estrutura financeira dependente basicamente do governo (Petrobras), já que os empresários privados não contribuíam para a criação de um modelo financeiro viável para as atividades de produção, transporte e distribuição de álcool, que fosse independente da Petrobras. Ao contrário, o que se viu foi o setor produtivo definhar sob o peso do sistema financeiro, que preferia financiar a rolagem da dívida pública a juros elevados e sem correr riscos, do que apoiar investimentos produtivos, industriais ou agrícolas, que envolvem riscos, como toda atividade empresarial produtiva que, de resto, só se pode viabilizar com juros muito inferiores aos oferecidos pelo governo ao sistema financeiro privado. Assim, também aí os bancos privados atuaram como simples multiplicadores de ativos financeiros estéreis, e os bancos oficiais (BNDES, Banco do Brasil e bancos estaduais), com base em critérios nem sempre transparentes, dissiparam recursos em projetos tecnicamente mal definidos, particularmente no 
tocante à parte agrícola e à logística de transporte e distribuição do combustível produzido, elevando desnecessariamente os custos.

O aumento do preço da gasolina e, principalmente, a crescente conscientização do público em geral em torno dos problemas ligados às emissões de $\mathrm{CO}_{2}$ e seus impactos sobre o clima estão fazendo que o setor alcooleiro readquira o vigor que teve quando foi criado o Proálcool. Parte desse vigor, entretanto, vem do interesse despertado pelos potenciais ganhos na exportação de álcool, sem que se analisem os impactos negativos que as monoculturas canavieiras provocarão, em médio e longo prazos, sobre o equilíbrio ecológico, com inevitáveis reflexos sobre a produção agrícola e, indiretamente, sobre o ciclo hidrológico.

No tocante ao petróleo, há registros históricos datados de 1864 dando conta da utilização de uma "lama preta oleosa" para iluminar residências, em Lobato, na Bahia.

Há, também, relatos sobre o que teria sido "o primeiro poço de petróleo" do Brasil, perfurado por um fazendeiro da região de Bofete, em São Paulo, em 1897 (Informação disponível em <http://www.brasilescola.com/brasil/historia-do-petroleo-no-brasil.htm>).

A institucionalização das atividades de exploração de petróleo no Brasil data de 1938, quando foi criado o Conselho Nacional do Petróleo (CNP), para avaliar pedidos de pesquisa e lavra de jazidas, e foram reguladas as atividades de refino, importação, exportação, transporte, distribuição e comercialização de petróleo e derivados. Por outro lado, ainda que não localizadas, as jazidas passaram a integrar o patrimônio da União. A indústria petrolífera brasileira propriamente dita só nasceu em 1953, com a criação da Petrobras e a instituição do monopólio da União sobre as atividades de pesquisa, lavra, refino, transporte e distribuição de petróleo e derivados. Até então as decisões relativas ao petróleo, no Brasil, dependiam, direta ou indiretamente, de políticas traçadas pelas corporações internacionais do setor aqui estabelecidas (Esso, Shell, Texaco etc.), que atuavam principalmente no segmento de distribuição de derivados. Graças aos investimentos da Petrobras em pesquisa e lavra e, sobretudo, à tecnologia desenvolvida pela empresa para a exploração em águas profundas, o Brasil alcançou, em 2006, a autossuficiência na produção de petróleo.

Quanto à energia nuclear, sua história, no Brasil, remonta à década de 1930, com a vinda de professores europeus para a Universidade de São Paulo, formando um núcleo do qual se originou a Secção de Física da Faculdade de Filosofia, Ciências e Letras (FFCL), que deu origem ao atual Instituto de Física dessa universidade.

Em 1956 foi criado o Instituto de Energia Atômica (IEA), para onde foram transferidos inúmeros físicos da Secção de Física da FFCL e engenheiros da Escola Politécnica. Em 1979, sob a forma de autarquia, o IEA passou à jurisdição da Secretaria de Ciência, Tecnologia e Desenvolvimento Econômico do Estado de São Paulo (atual Secretaria de Indústria, Comércio, Ciência e Tecno- 
logia (SEICCT)), com o nome de Instituto de Pesquisas Energéticas e Nucleares (Ipen). Atualmente esse Instituto é vinculado à Comissão Nacional de Energia Nuclear (CNEN) e segue diretrizes definidas por um Conselho Técnico-Administrativo (CTA), onde têm assento membros da diretoria executiva do próprio instituto, ao lado de representantes de USP, Fiesp, SEICCT e CNEN. Para fins de ensino de pós-graduação, o IPEN continua ligado à USP (IPEN, <http:// www.ipen.br/sitio/index.php?idm=3>).

Em 1966 instituiu-se o Centro de Energia Nuclear na Agricultura (Cena), junto à Escola Superior de Agricultura da USP, em Piracicaba.

Nas décadas de 1940, 1950 e 1960, o governo federal criou, no Rio de Janeiro, o Centro Brasileiro de Pesquisas Físicas (CBPF) (1949), o Conselho Nacional de Pesquisas (CNPq) (1951), a Comissão Nacional de Energia Nuclear (CNEN) (1956), o Instituto de Radioproteção e Dosimetria (IRD) (1960) e o Instituto de Energia Nuclear (IEN) (1962). Em 1953 criou-se em Belo Horizonte o Instituto de Pesquisas Radiológicas (IPR), ligado à Universidade Federal de Minas Gerais, posteriormente transferido para a extinta Nuclebras e atualmente vinculado à CNEN, sob a denominação de Centro de Desenvolvimento de Tecnologia Nuclear (CDTN).

Em 1971, quando CNEN e Furnas Centrais Elétricas receberam a incumbência de implantar a central nuclear de Angra I, contratada com a Westinghouse, criou-se a Companhia Brasileira de Tecnologia Nuclear (CBTN), com a atribuição de planejar e implantar no país um programa de geração eletronuclear, em escala adequada para cobrir a demanda de energia elétrica, quando o potencial hidroelétrico estivesse plenamente aproveitado. Essa companhia foi extinta em 1975, nascendo em seu lugar a Nuclebras, já no clima das negociações que deram origem ao acordo nuclear com a Alemanha.

A nova empresa coordenou um programa que resultou na construção de uma fábrica de componentes pesados (Nuclep) e das centrais nucleares de Angra II e Angra III (Carvalho, 1987).

Do início do século passado até meados da década de 1950, o sistema elétrico brasileiro foi controlado por grupos estrangeiros. Em 1950, a capacidade total do sistema era de apenas $1.882 \mathrm{MW}$, e os grupos controladores não se interessavam por investir em expansões, o que inviabilizava os processos de industrialização e substituição de importações que então ganhavam impulso. $\mathrm{O}$ empresariado industrial começou então a pressionar o governo, para que esse assumisse o controle do sistema e o expandisse.

Assim, a partir de 1955, o Estado entrou no setor, investindo em sua modernização e estruturando-o sobre um conjunto de empresas públicas, que expandiram rapidamente sua capacidade, atingindo 93.000 MW em 2005

Essa evolução estimulou o desenvolvimento da tecnologia nacional nos campos da engenharia de centrais hidroelétricas, indústrias de material elétrico e componentes mecânicos e eletrônica de instrumentação e controle. 
Consolidou-se, assim, no Brasil, uma importante indústria de equipamentos eletromecânicos, criaram-se firmas de engenharia e de consultoria, além de órgãos de pesquisa e laboratórios ligados a instituições públicas e a empresas privadas.

Nesse processo formaram-se engenheiros e técnicos qualificados nas áreas de projeto, construção e operação de usinas geradoras e sistemas de transmissão e distribuição de energia elétrica.

O uso da eletricidade permitiu que o Brasil passasse de país essencialmente exportador de produtos agrícolas para aos poucos converter-se em país industrializado, propiciando notáveis transformações sociais.

\section{Considerações finais e conclusão}

Os relatórios do Painel Intergovernamental sobre Mudanças Climáticas das Nações Unidas (IPCC/UN) deixam claro que a finitude das fontes de energia nas quais esteou-se o desenvolvimento até o presente tem levado o público em geral a, progressivamente, tomar consciência de que a vida no Planeta depende do delicado e frágil equilíbrio dos ecossistemas que compõem a biosfera.

O caráter finito dos recursos naturais e os impactos ambientais provocados pela exploração e consumo de petróleo, gás natural e carvão mineral deixa evidente que essas fontes deverão ser gradativamente abandonadas; e que é indispensável investir seriamente no desenvolvimento de fontes de energia que sejam renováveis e limpas.

Por outro lado, o crescimento deve ser limitado a um estado de equilíbrio (Daly, 2005), até porque o desenvolvimento não depende necessariamente de crescimento, mas sim de outros fatores, como a melhoria da educação, um maior acesso à informação, melhor qualidade do produto, racionalidade e manutenção de sistemas de transporte de passageiros e de carga, e assim por diante.

Isso deve ser alcançado mediante aperfeiçoamentos tecnológicos destinados a reduzir o consumo e a intensidade energética nos setores produtivos, para que esses possam converter recursos naturais (energia primária e matérias-primas) em energia utilizável e produtos acabados, com o mínimo impacto ambiental e eficiência máxima, tendo como o principal objetivo a qualidade de vida dos consumidores.

\section{Referências}

ANTHONY, D. et al. The Origin of Horseback Riding. Scientific American, Dec. 1991. ARISTÓTELES. Politics, II, 1.2 - 1.2.3; V, 1.10 - 1.12 e VII. 14 - 15/Tradução inglesa de B. Jowett, 1885 (Dover, 2000).

BARGHINI, A. Le origini del motore a vapore. Le Scienze, v,36, aug. 1971.

BOWMAN, D. et al. Fire in the Earth System. Science, v.324, 24 apr. 2009.

CARVALHO, J. F. A exploração das florestas através dos tempos. Jornal do Brasil, Rio de Janeiro, 5 dezembro 1983. 
CARVALHO, J. F. O acordo Nuclear Brasil Alemanha: uma anatomia do desenvolvimento nuclear brasileiro.In: . O Brasil nuclear. Porto Alegre: Tche, 1987.

CIPOLLA, C. M. The economic history of world population. s. 1.: Pelican Books, 1964.

CONDORCET. Esquisse d'un tableau historique des progrès de l'esprit humain. 4.ed. Paris: Agasse, 1798.

DALY, H. Economics in a Full World. Scientific American, Sept. 2005.

DURAND, J. D. Historical Estimates of World Population, University of Pennsylvania Population Center, Analytical and Technical Reports, Number 10. 1974.

HAUB, C. How Many People Have Ever Lived on Earth? Population Today, February, 1995.

HÉMERY, D.; DEBEIR, J.- C.; DÉLEAGE, J.- P. Uma história da energia. Brasília: Ed. Universidade de Brasília, 1991.

JACOMY, B. Une histoire des techniques. Paris: Seuil, 1990.

KUNSTLER, J. H. La fin du pétrole - Le vrai défi du XXI ${ }^{\mathrm{e}}$ siècle. Paris: Plon, 2005.

MENEZES, T. J. B. Etanol, o combustivel do Brasil. s. 1.: Editora Agronômica Ceres, 1980.

PETROLEUM INDUSTRY. 2007. Disponível em: <http://en.wikipedia.org/wiki/ Petroleum_industry>.

PLATÃO. Laws. s. 1.: Dover, 2006.

ROSA, E. et al. Energy and society. Annual Review of Sociology, n.14, 1988.

UNITED NATIONS Population Division, 1999

RESUMO - Neste artigo são examinadas certas correlações entre o consumo de energia e o estágio de desenvolvimento de uma sociedade, seus costumes e o grau de industrialização do país em que vive. Até as últimas décadas do século passado, pensava-se que "sociedades mais evoluídas consomem necessariamente mais energia". Este pensamento ficou tão arraigado que chegava-se ao ponto de considerar que energia era um fim em si mesma e, por vezes, os cenários de alto consumo de energia eram chamados de "cenários otimistas", quando, na verdade, deveria ser o oposto, pois é evidente que, além de implicarem maiores agressões ao meio ambiente, tais cenários exigirão grandes sacrifícios da sociedade. É certo que o desenvolvimento das sociedades ainda subdesenvolvidas requer um consumo de energia crescente em termos per capita; entretanto, uma vez alcançado uma razoável qualide de vida, esse consumo pode estabilizar-se num estado estacionário.

PALAVRAS CHAVE: Evolução do consumo de energia, Intensidade energética e nível de desenvolvimento da sociedade ao longo do tempo.

ABSTRACT - This article reviews some correlations between the energy consumption and the stage of development of a society, its customs and the degree of industrialization of the country. Until the last decades of the last century, it was thought that "most developed societies necessarily consume more energy". This thought was so ingrained that it came to the point of considering that energy was an end in itself and sometimes 
the scenarios of high energy consumption were called "optimistic scenarios", but in fact it should be the opposite because it is evident that in addition to involve greater environmental harm, such scenarios require great sacrifices of society. It is true that the development of societies still sub-developed requires increasing energy consumption in per capita terms, however, once attained a reasonable quality of life, this consumption can stabilize at a steady state.

KETWORDS: Evolution of energy consumption, Energy intensity and state of development of a society, over time.

Joaquim Francisco de Carvalho é doutor em Energia pelo Instituto de Energia e Ambiente da USP, é pesquisador associado a esse Instituto e pós-doutorando pela COPPE/ UFRJ. @-jfdc35@uol.com.br

Recebido em 27.8.2014 e aceito em 15.9.2014.

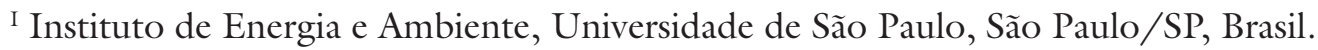


